\title{
False negative rate in cervical cytology
}

\author{
YOLANDA VAN DER GRAAF,* G P VOOIJS $\dagger$ \\ From the Departments of ${ }^{*}$ Social Medicine and $\dagger$ Pathology, University of Nijmegen, Nijmegen, The Netherlands $s_{0}$
}

SUMmARY All women in Nijmegen, The Netherlands, with a histological diagnosis of severe dys- $\frac{\overrightarrow{\vec{\omega}}}{\mathrm{\omega}}$

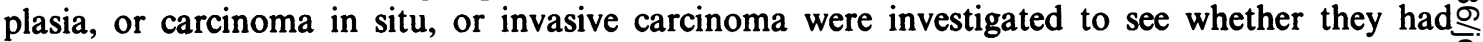
participated in a population screening programme. Within two years of diagnosis of a negative? cervical smear, 45 women were found to have histologically confirmed severe epithelial abnormality $\dot{0}$ of the cervix. From the same population as these apparently false negative cases, the number of true + positive cases was available, and hence the sensitivity of cervical screening for severe dysplasia, or $\stackrel{+}{\omega}$ carcinoma in situ, and invasive carcinoma could be assessed. This was found to be $83 \%$ after two years. The laboratory procedures which led to the high sensitivity for the cervical cytodiagnosis were ${ }_{-}^{\supset}$ analysed.

Experienced sample takers and cytotechnologists are very important and can reduce sample and을. screening errors. A good administrative system is necessary to guarantee proper follow up for $\vec{\varphi}$ women with abnormal findings in their cervical smears.

Over the past 30 years the false negative rate in cervical cytodiagnosis has been the subject of numerous studies. Estimates for the false negative rate range from 2 to $55 \% .^{1-10}$ For a long time the large number of false negative cytological diagnoses was a major obstacle to the acceptance and large scale implementation of cervical cancer screening programmes.

In most studies only the screening history of women with invasive cancer of the cervix was reviewed. To determine with maximal possible accuracy the sensitivity of the cytological diagnosis, however, the total number of women from the same population, in the same time period, who were cytologically tested and confirmed to have severe intraepithelial neoplasia or invasive cancers ("true positives") should be known as well. Theoretically, histological examination of each cervix examined cytologically would be needed to calculate the true sensitivity. As this is clearly impossible the sensitivity has to be estimated in an indirect way. A feasible and acceptable procedure is to follow up all women with a negative cervical smear, provided the follow up is sufficiently long. In the Nijmegen population screening programme, during the years 1976 to 1985 all women aged 35 to 55 were invited every three years for a cervical smear. We had the opportunity to trace

Accepted for publication 4 September 1986 all women with negative cytology who subsequently developed a severe epithelial abnormality.

\section{Patients and methods}

Since 1976 a screening programme for cervical cancer for all women aged 35 to 55 years has been in progress in the city of Nijmegen and adjacent communities in The Netherlands. The Nijmegen region comprises 735000 inhabitants. About 88000 women wereo invited to participate. Smears were taken every three years. Overall attendance rates were $74 \%$ and $67 \%$ in first and second screening, respectively.

A single cervical smear was taken with a slightlyo modified pointed Ayre's spatula. The specimens were $\square$ obtained by trained sample takers. The smears were을 processed at the cytopathology laboratory of the department of pathology, University of Nijmegen, and screened by experienced cytotechnologists.

In cases of abnormal cytological findings the gen-N eral practitioner was informed, who was theno responsible for the follow up. If cytological findingso were consistent with severe dysplasia, carcinoma in situ, or invasive cancer referral to a gynaecologist was $\stackrel{\text { f }}{?}$ recommended. In cases of cytological diagnoses con- 0 sistent with mild or moderate dysplasia the genera $\overline{0}$ practitioner was requested to take a repeat smear尺 after six or three months, respectively. The laboratoryd checked to see whether the advice had been followed and if not, the general practitioner was again con- 
tacted. Cytology reports were graded as follows: grades I and II, no or slight abnormalities; grade IIIA, mild to moderate dysplasia; grades IIIB and IV, severe dysplasia and carcinoma in situ; grade V, invasive cancer. Mild dysplasia corresponds with CIN1, moderate dysplasia with CIN2, and severe dysplasia or carcinoma in situ with CIN3 (table 1).

To analyse the validity of the smear this classification was arranged into two categories. Those smears of which the report recommended no further follow up (grades I and II) were considered to be negative and those smears for which the report requested an immediate repeat smear or a histological examination (grades IIIB, IV, and V) were considered to be positive. Women with a diagnosis of mild or moderate dysplasia were not included, because a follow up smear was advised within three to six months. To estimate the sensitivity of the cervical smear information has to be obtained on the number of true positive results and the number of false negative results. True positive results are all positive smears for which a cytological diagnosis of severe dysplasia, carcinoma in situ, or invasive cancer is confirmed by histological diagnosis: in other words, the number of test positive results minus the false positive diagnoses. These data can easily be obtained from the follow up registration of the screening programme. The ratio between the number of true positive and test positive results is the predictive value of a positive test.

To calculate the number of false negative screening results we made use of a cancer registry. This registry was kept for all women with a tissue diagnosis of severe dysplasia, carcinoma in situ, or invasive cancer of the cervix. ${ }^{11}$ Tissue diagnoses were obtained by histological examination of biopsy specimens taken through a speculum, biopsies directed by colposcopy, or cervical curettings - sometimes, directly after a

Table 1 Cytological diagnoses during first and second screening rounds

\begin{tabular}{|c|c|c|c|}
\hline $\begin{array}{l}\text { Papanicolaou } \\
\text { class }\end{array}$ & $\begin{array}{l}\text { Squamous epithelial } \\
\text { changes consistent } \\
\text { with: }\end{array}$ & $\begin{array}{l}\text { First } \\
\text { screening } \\
\text { round }\end{array}$ & $\begin{array}{l}\text { Second } \\
\text { screening } \\
\text { round }\end{array}$ \\
\hline \multirow[t]{2}{*}{ I and II: } & $\begin{array}{l}\text { No epithelial } \\
\text { abnormalities }\end{array}$ & 62.039 & $57 \cdot 048$ \\
\hline & $\begin{array}{l}\text { Atypical squamous } \\
\text { cells present } \\
\text { Atypical squamous } \\
\text { metaplasia }\end{array}$ & $99 \cdot 2 \%$ & $98.9 \%$ \\
\hline IIIA: & $\begin{array}{l}\text { Mild dysplasia } \\
\text { Moderate dysplasia }\end{array}$ & $\begin{array}{l}324 \\
0.5 \%\end{array}$ & $\begin{array}{l}493 \\
0.9 \%\end{array}$ \\
\hline$I I I B, I V, V$ & $\begin{array}{l}\text { Severe dysplasia } \\
\text { Carcinoma in situ } \\
\text { Invasive cancer }\end{array}$ & $\begin{array}{l}189 \\
0.3 \%\end{array}$ & $\begin{array}{l}130 \\
0 \cdot 2 \%\end{array}$ \\
\hline Total & & $62 \cdot 552$ & $57 \cdot 671$ \\
\hline
\end{tabular}

suspicious cytological result, cone biopsy or hysterectomy was performed. In cases of more than one tissue analysis the most severe diagnosis was used for the calculation of the sensitivity.

The cancer registry was linked to the files of the screening programme. For those women with a tissue diagnosis of severe dysplasia, carcinoma in situ, or invasive cancer who had participated in the screening programme, the cytological diagnosis of the smear, made up to 48 months before the tissue diagnosis, was recorded. Sensitivity was then calculated in the usual way-as the ratio between the number of true positive results and the sum of true positive and false negative results. When the number of false negative results is known, specificity can be calculated as the ratio between the sum of test negative and false positive results and the number of true negative results.

\section{Results}

Between 1976 and 1983 two three-year screening rounds were completed. Participation rates were $74 \%$ in the first screening round (1976-79) and $67 \%$ in the second (1979-82). In total, 120223 smears were made. Of these, 319 smears were classified as positive and 119087 smears as negative. In 817 women the cytological findings were consistent with mild or moderate dysplasia. The follow up results of these women will be evaluated in a separate study. In $20 \%$ of women with a cytological diagnosis of moderate dysplasia severe abnormalities confirmed by histological examination were subsequently discovered.

In $235(74 \%)$ of the 319 women with positive results cytological findings were confirmed by tissue diagnoses and were therefore regarded as true positive results. In 76 smears $(24 \%)$ cytological diagnosis was not confirmed, and these smears were regarded as false positive results. In 32 of these, several repeat smears did not show any epithelial abnormalities. In 44 women histological examination was carried out. In 18 women who had a hysterectomy and in three women who had a cone biopsy histology did not show severe abnormalities. In 16 women two or more biopsies directed by colposcopy were obtained before the cytological result was regarded as false positive. In two women a blind biopsy, followed by negative smears, did not confirm the positive cytology. In five women cervical curettings, followed by negative smears, did not confirm the positive test result. In nine $(3 \%)$ follow up data were not available (table 2 ).

From these data the predictive value of the positive test results could be computed by calculating the ratio between the number of true positives and test positives. In the first period the predictive value was $82 \%$, whereas in the second period it was $67 \%$. The value in the second period is lower because of the lower preva- 
Table 2 No of true positive results, false positive results, and test positive results plus predictive value of positive diagnosis $(\geqslant$ severe dysplasia) in first and second screening round

\begin{tabular}{llllll}
\hline Screening round & Test positive & Unknown & True positive & False positive & Predictive value \\
\hline First & 189 & 8 & 148 & 33 & $82 \%$ \\
Second & 130 & 1 & 87 & 43 & $67 \%$ \\
Total & 319 & 9 & 235 & 76 & 0 \\
\hline
\end{tabular}

lence of epithelial abnormalities in the second period (Bayes' theorem ${ }^{12}$ ).

Histologically confirmed cases of severe dysplasia, carcinoma in situ, and invasive cancer, diagnosed after a given interval after a cytological smear had been diagnosed as negative, were considered to be missed positive results (table 3 ).

Sensitivity of cytological screening for the detection of these three epithelial abnormalities was calculated separately and as a group at 24,36 , and 48 months of follow up (table 4).

Sensitivity was relatively high when only invasive cancers were considered to be false negative in the analysis of diagnosis after 24,36 , and 48 months. Sensitivity figures were $99 \%, 98 \%$, and $97 \%$, respectively.

A screening programme, however, should not only be directed towards the detection of invasive cancer but should also include the detection of severe epithelial abnormalities, which can be considered as potential precursors of cervical carcinoma. Sensitivity figures were therefore calculated for a broader spectrum of epithelial lesions than was the case in earlier reports. When all severe epithelial abnormalities (severe dysplasia, carcinoma in situ, and invasive cancers) diagnosed within 24,36 , and 48 months after a negative smear was made, were defined as false negative results, the sensitivity was calculated to be $94 \%$, $89 \%$, and $84 \%$, respectively. When only carcinoma in situ and invasive cancers were considered, sensitivity figures after 24,36 , and 48 months were $95 \%, 92 \%$, and $89 \%$, respectively.

Table 3 Interval in months between negative cytological diagnosis (<slight dysplasia) and histological diagnosis of severe dysplasia, carcinoma in situ, or invasive cancer

\begin{tabular}{lllllll}
\hline \multicolumn{7}{c}{$\begin{array}{l}\text { Interval in months since negative cytological } \\
\text { diagnosis }\end{array}$} \\
\cline { 2 - 7 } $\begin{array}{l}\text { Histological } \\
\text { diagnosis }\end{array}$ & $0-12$ & $13-24$ & $25-36$ & $37-48$ & $>48$ & Total \\
\hline $\begin{array}{l}\text { Severe } \\
\text { dysplasia }\end{array}$ & 1 & 3 & 5 & 8 & 4 & 21 \\
$\begin{array}{l}\text { Carcinoma } \\
\text { in situ }\end{array}$ & 2 & 7 & 7 & 4 & 7 & 27 \\
$\begin{array}{l}\text { Invasive } \\
\text { cancer }\end{array}$ & $2 *$ & $1 \dagger$ & $2 \ddagger$ & $3 \S$ & & 8 \\
\begin{tabular}{l} 
Total \\
\hline Clinical staging (FIGO):
\end{tabular} & 5 & 11 & 14 & 15 & 11 & 56 \\
\hline Twice stage IIB. †Stage IA. $¥$ Twice stage IB. 8 Stage IIB and twice \\
stage IV.
\end{tabular}

\section{Discussion}

The estimates of sensitivity were high compared with $\overrightarrow{0}$ those of previous reports. The estimate could have $\overrightarrow{\vec{\omega}}$ been biased because of three inaccuracies in the calcu- $\omega$ lation of the false negative results. Firstly, cases were $\vec{?}$ included which became apparent during follow up, but which were still in a preclinical non-detectable phase at the time when the negative cervical smear was made. Secondly, cases which were missed at the $\omega_{\infty}$ time the cervical smear was taken but did not become $\mathrm{O}$ evident during the time of follow up. Thirdly, in a number of women the epithelial abnormality might $\rightarrow$ have regressed during the follow up.

The longer the follow up, the more cases will $\overrightarrow{\vec{\theta}}$ become evident that were in a preclinical, non- $\mathscr{\infty}$ detectable phase at the time of the test and which. cannot be distinguished from the truly missed cases that became evident during the same follow up. Day ${ }^{13}$ suggested a method for calculating sensitivity that largely compensates for the inaccuracies men- 0 tioned above. It is based on incidence rates alone. $\stackrel{\mathbb{Q}}{\square}$

For cervical cancer, this method is probably of lim- $\overrightarrow{\overrightarrow{0}}$ ited value as incidence rates in the absence of screen- 3 ing must be known, so it can only be applied when invasive cancers are defined as false negative results? and not when preinvasive epithelial abnormalities are considered as well. From our sensitivity figures it can? be concluded that the quality of cervical screening is 3 . high compared with the results reported by others. ${ }^{1248-10}$ Differences in screening methods and $\frac{}{3}$ classification would not account for the differences in sensitivity. Although the measures taken as part of 3 the screening programme for quality control in the

Table 4 Sensitivity figures (\%) calculated for different groups of missed epithelial abnormalities after 24,36, and 48 months

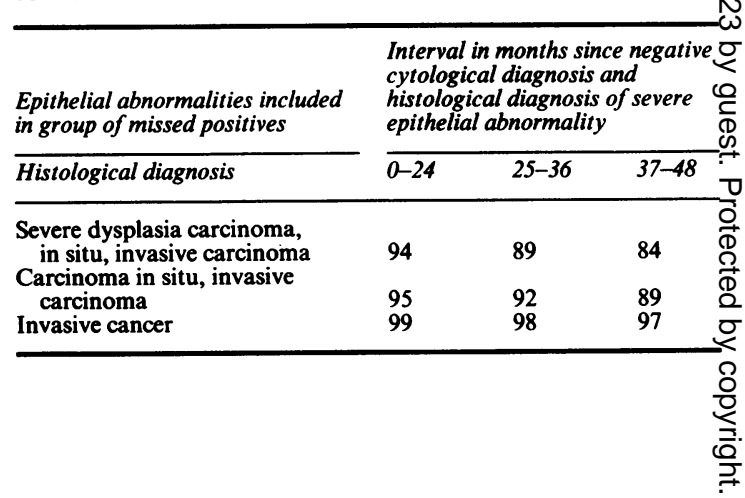


department of pathology of this university are time consuming, they have been successful.

The smears in the population screening project were made by experienced cytosmear takers. Some of them take more than 3000 cervical smears every year. The number of unsatisfactory smears and the number of smears without endocervical columnar cells is evaluated for each cytosmear taker and compared with the results of the other samplers. When the number of unsatisfactory smears or the number of smears without endocervical columnar cells is too high, the reasons for the lower quality are analysed and new instructions are given. ${ }^{14-16}$ In this way sample error can be considerably reduced.

Increasing sensitivity by taking two samples at a time, as has been suggested, was considered to be too expensive, ${ }^{717-20}$ because it increases screening time by about $60 \%$, and other measures to increase the quality of the smear were as effective.

Follow up results were registered by the laboratory, and if no follow up data became available the reasons for this delay were traced and the general practitioner was contacted. In the past the follow up of cases of mild, moderate, and severe epithelial abnormality has been monitored. This work was time consuming but was very worthwhile as more than $90 \%$ of the recommended follow up was completed.

In cases with minimal changes and slight epithelial atypia the compliance with the advised follow up (a repeat smear after one year) was not checked by the laboratory. In only $27 \%$ of these cytological diagnoses was follow up spontaneously done. In future, the follow up of these smears may have to be monitored by the laboratory as well, as these women have a considerably higher risk of developing cervical abnormalities. ${ }^{21}$ Other workers have noticed the problem of the incomplete follow up as well. Recently Elwood et al reported that of 1062 women with cytological diagnoses consistent with invasive cancer and other highly atypical and moderately atypical abnormalities, only $628(59 \%)$ had been followed up satisfactorily. ${ }^{22}$ Ellman et al reported that of 100 women with invasive cancer of the cervix, 13 with a cytological diagnosis of suspected cervical cancer had not had adequate follow up. ${ }^{23}$

The smears were screened by experienced cytotechnologists, who examined smears from the population screening programme as well as those submitted by the hospital and family physicians. The daily workload was set at an average of 25 cases a day; quite a lot of time was spent on education. All smears with false negative results and obviously underestimated diagnoses are rescreened and used for discussion by the whole group.

In The Netherlands a cervical smear is recommended every three years for women aged between 35 and
55. Our results show that this policy works well. Many authors base the length of the recommended interval on the high percentage of false negative smears in women with invasive carcinoma..$^{64-27} \mathrm{We}$ do not consider this to be a proper procedure. It is well known that taking a satisfactory cervical smear from women with invasive carcinoma is more difficult because of the admixture of blood, necrotic material, cellular debris, etc. ${ }^{2425}$ An epithelial abnormality may only be represented by a small number of abnormal cells and can easily be missed.

To reduce the problem of false negative diagnosis quality control of the taking of the cytological sample and the cytological diagnostic procedure is important. To reduce the consequences of false negative results it may be advisable to make a repeat smear quite soon after the initial smear-for example, after one year. After two negative smears a longer interval of three years or even five years seems justified. ${ }^{28}$ The interval should be based on the total period entailed in the genesis of a cervical cancer and on the precursor lesions of invasive carcinoma. Some authors have calculated the average interval between mild, moderate, and severe dysplasia and carcinoma in situ to be three to four years. ${ }^{29} 30$

Using a three year interval, the possibility for the diagnosis of a preclinical non-invasive epithelial abnormality is greatly increased, provided the quality of cervical cytology is well controlled and the series of cervical cytological examinations is started within five years after the start of regular sexual contact.

\section{References}

1 Figge DC, Bennington JL, Schweid AI. Cervical cancer after initial negative and atypical vaginal cytology. Am J Obstet Gynecol 1970;108:422-8.

2 Coppleson LW, Brown B. Estimation of the screening error rate from the observed detection rates in repeated cervical cytology. Am J Obstet Gynecol 1974;119:953-8.

3 Shulman JJ, Leyton M, Hamilton R. The Papanicolaou smear: An insensitive case-finding procedure. Am J Obstet Gynecol 1974;120:446-51.

4 Husain OAN. Quality control in cytological screening for cervical cancer. Tumori 1976;62:303-14.

5 Rylander E. Negative smears in women developing invasive cervical cancer. Acta Obstet Gynecol Scand 1977;56:115-8.

6 Berkowitz RS, Ehrmann RL, Lavizzo-Mourey R, Knapp RC. Invasive cervical carcinoma in young women. Gynecol Oncol 1979;8:311-6.

7 Davis JR, Hindman WM, Paplanus SH, Trego DC, Wiens JL, Suciu TN. Value of duplicate smears in cervical cytology. Acta Cytol 1981;25:533-8.

8 Morell ND, Taylor JR, Snyder RN, Ziel HK, Saltz A, Willie S. False-negative cytology rates in patients in whom invasive cervical cancer subsequently developed. Obstet Gynecol 1982;60:41-5.

9 Cecchini S, Palli D, Casini A. Cervical intraepithelial neoplasia III. An estimate of screening error rates and optimal screening interval. Acta Cytol 1985;29:329-33. 
10 Gay D, Danos LM, Goellner JR. Analysis of false-negative cervical cytology at the Mayo clinic during a four-year period. Acta Cytol 1985;29:652.

II Graaf Y van der, Klinkhamer PJJM, Vooijs GP. Effect of population screening for cancer of the uterine cervix in Nijmegen, The Netherlands. Prev Med 1986;15:582-90.

12 Weinstein MC, Fineberg HV, Elstein AS, et al. Clinical decision analysis. Philadelphia: WB Saunders Company, 1980.

13 Day NE. Estimating the sensitivity of a screening test. J Epidemiol Community Health 1985;39:364-6.

14 Elias A, Linthorst G, Bekker B, Vooijs GP. The significance of endocervical cells in the diagnosis of cervical epithelial changes. Acta Cytol 1983;27:225-9.

15 Vooijs GP, Elias A, Graaf Y van der, Veling S. Relationship between the diagnosis of epithelial abnormalities and the composition of cervical smears. Acta Cytol 1985;29:323-8.

16 Vooijs GP, Elias A, Graaf Y van der, Poelen-Berg van de M. Samplers' influence on the cellular composition of cervical smears. Acta Cytol 1986;30:251-7.

17 Sedlis A, Walters AT, Balin H, Hontz A, LoSciuto L. Evaluation of two simultaneously obtained cervical cytological smears. Acta Cytol 1974;18:291-6.

18 Shulman JJ, Hontz A, Sedlis A, Walters AT, Balin H, LoSciuto L. The Pap smear: take two. Am J Obstet Gynecol 1975;121:1024-8.

19 Luthy DA, Briggs RM, Buyco A, Eschenbach DA. Cervical cytology. Increased sensitivity with a second cervical smear. Obstet Gynecol 1978;51:713-7.

20 Beilby JOW, Bourne R, Guillebaud J, Steele ST. Paired cervical smears: a method of reducing the false-negative rate in population screening. Obstet Gynecol 1982;60:46-8.
21 Cotton RE, Elwood JM, Jones GM. Results of delayed follow up of abnormal cervical smears. Br Med J 1986;292:799-800.

22 Elwood JM, Cotton RE, Johnson J, Jones GM, Curnow J, Beaver MW. Are patients with abnormal cervical smears adequately managed? $\mathrm{Br}$ Med $J$ 1984;289:891-4.

23 Ellman R, Chamberlain J. Improving the effectiveness of cervical cancer screening. Journal of the Royal College of General Practitioners 1984;34:537-41.

24 Berkeley AS, LiVolsi VA, Schwartz PE. Advanced squamous cell carcinoma of the cervix with recent normal Papanicolaou tests. Lancet 1980;ii:375-6.

25 Rubio CA. False negatives in cervical cytology: can they be avoided? Acta Cytol 1981;25:199-202.

26 Benoit AG, Krepart GV, Lotocki RJ. Results of prior cytologic screening in patients with a diagnosis of stage I carcinoma of the cervix. Am J Obstet Gynecol 1984;148:690-4.

27 Paterson MEL, Peel KR, Joslin CAF. Cervical smear histories of 500 women with invasive cervical cancer in Yorkshire. $\mathrm{Br}$ Med $J$ 1984;289:896-8.

28 Hakama M, Chamberlain J, Day NE, Miller AB, Prorok PC. Evaluation of screening programmes for gynaecological cancer. Br J Cancer 1985;52:669-73.

29 Patten SF. Dysplasia of the uterine cervix. New concepts in gynecological oncology: Philadelphia: A Davis, 1986.

30 Richart RM. Natural history of cervical intraepithelial neoplasia. Clin Obstet Gynecol 1967;10:748-84.

Requests for reprints to: Dr GP Vooijs, Department of Pathology, University of Nijmegen, Geert Grooteplein Zuid 24, 6525 GA Nijmegen, The Netherlands. 